\title{
Good Governance and Happiness in Nations: Technical Quality Precedes Democracy and Quality Beats Size
}

\author{
Jan C. Ott
}

Published online: 28 May 2009

(C) Springer Science+Business Media B.V. 2009

\begin{abstract}
Average happiness differs markedly across nations and there appears to be a system in these differences. This paper considers the role of quality of governance, and in particular the role of technical quality as opposed to democratic quality. A comparison of 127 nations in 2006 shows strong correlations between the quality of governance and average happiness of citizens. The correlation between technical quality and happiness is +0.75 and the correlation between democratic quality and happiness is +0.60 . Technical quality correlates with happiness in rich and poor nations, while democratic quality only correlates with happiness in rich nations. The quality of governance appears to be more important for happiness than the size of governments: the relation between quality and happiness is independent of size, while the relation between size and happiness fully depends on quality. The correlation between technical quality and happiness appears to be independent of culture; it exists not only in western nations, but also in Eastern Europe, Latin America, the Middle East, Asia and Africa. This indicates that technically good governance is a universal condition for happiness, and not just a western ideology. Democratic quality adds substantially to the positive effects of technical quality once technical quality has reached some minimal level.
\end{abstract}

Keywords Happiness - Utilitarianism - Good governance · Voice and accountability · Political stability · Government effectiveness · Regulatory quality · Rule of law · Control of corruption - Size of governments · Wealth · Gender equality

\section{Introduction}

According to utilitarian moral philosophy, governments have the duty to promote "the greatest happiness for the greatest number". This classic view is gaining ground in modern times. A contemporary advocate is economist Richard Layard, who wants to shift the

J. C. Ott (ه)

Erasmus University Rotterdam, Rotterdam, The Netherlands

e-mail: ott@fsw.eur.nl; jan.ott@planet.nl 
direction of public policy away from economic goals like wealth, to wider "well-being" and "happiness". Layard (2005) advocates an evidence-based utilitarian policy approach and demonstrates how the insights of happiness science, can be incorporated in governments policies.

In this line a vivid discussion is going on about what governments should do to create greater happiness for a greater number. Utilitarians like Layard (2005) and Paul Martin (2005) follow Richard Easterlin (1974) in his assessment that economic growth in wealthy nations is no longer contributing to happiness. They want governments to discourage people from getting involved in a useless rat race, by raising taxes for those working more than a specified number of hours of paid work. In the "Well-being manifesto for a flourishing society" by the New Economic Foundation (2004) similar proposals are further developed. Other scientists have different priorities; e.g., Veenhoven (1999) prioritizes freedom and individual autonomy.

A somewhat neglected issue in such discussions is the quality of governments "as such", apart from the actual policies that are to be pursued. Some specific aspects of quality have received considerable attention, like democracy and corruption, but general quality of governance in nations is not a common subject in research. The complexity of defining and measuring quality, in a systematic and value-free manner, has probably acted as deterrent in this field. In the last 10-15 years this quality has received more political attention; in particular as a key-factor for the effectiveness of development aid and economic growth in general. In this context, the World Bank has developed indicators of good governance, and on the basis of these data experts estimate that a nation improving the quality of its governance from a relatively low level to an average level, can almost triple income per capita in the long term, and similarly reduce infant mortality and illiteracy. Kaufmann (2005, myth 4, p. 1) makes the following observation about causality: "In fact, the evidence points to the causality being in the direction of better governance leading to higher economic growth. A number of emerging economies, including the Baltic states, Botswana, Chile and Slovenia, have shown that it is possible to reach high standards of governance without yet having joined the ranks of wealthy nations".

The spectacular impact of the quality of governance on wealth suggests that the quality of governance may also have a positive impact on happiness, since wealth is important for happiness, but also since governments can provide for additional conditions, like safety, healthcare and a minimal level of social equality and justice. At this point Bruno Frey (2008) makes an interesting distinction between two sources of happiness: "outcome utility" and "procedural utility". "Outcome utility" is created by instrumental goods and services, often defined in monetary terms and in particular by income. Frey defines procedural utility as “... the well-being gained from living and acting under institutionalized processes that also contribute to a positive sense of self and address the innate needs for autonomy, relatedness, and competence". The quality of governments is obviously an important factor, not just for outcome utility but also for procedural utility.

\subsection{Earlier Research}

Research on the impact of governance on happiness has been done by Helliwell and Huang (2008). In an article "How's Your Government? International Evidence Linking Good Government and Well-being", they compared data about life-satisfaction in 75 
nations from the World Values Surveys (Inglehart et al. 2004) in the years 1981-2000, with data about good governance from the World Bank for the years 1996-2004. They used an average of six World Bank-indicators as an index of good governance and found a strong linear correlation between this indicator and average life-satisfaction in nations. Next Helliwell and Huang (2008) constructed two specific sub-indicators. GovDem (a) as the average of "Voice and Accountability" and "Political Stability", which reflects the operation of the democratic process. GovDo (b) is the average of the other four components: "Government Effectiveness", "Regulatory Quality", "Rule of Law", and "Control of Corruption". GovDo is related to the delivery of government services and providing the institutional framework within which individuals, enterprises and communities connect. Helliwell and Huang (2008) found that the "GovDo-elements" are relatively more important for poor nations, while the "GovDem-elements" are relatively more important for wealthier nations. They assume that democracy becomes interesting and important only once government has reached a reasonable level of technical quality.

\subsection{Further Steps}

In this paper I will expand on this research line in the followings ways: Firstly, I will check the robustness of the above findings, replicating the analysis of Helliwell and Huang for a larger set of nations and using another measure of happiness. Secondly, I will assess how universal this relationship is, by assessing the impact of culture and wealth on this relation. Thirdly, I will inspect to what extent the effect of quality of governance on happiness depends on the size of government. Finally, I will explore some of the ways in which good governance can affect happiness.

\subsection{Research Questions}

In this paper the following questions are addressed:

(a) Does good governance go together with greater happiness of citizens? Can the results of Helliwell and Huang be replicated in a larger sample of nations and using a different measure of happiness?

(b) Are technical and democratic aspects of governance equally strongly related to happiness?

(c) Does higher quality increase monotonously with greater happiness, or are there indications of diminishing or increasing utility?

(d) Are the relations universal, or do they exist only in western cultures or in wealthy nations?

(e) Do the correlations depend on the size of governments in nations?

(f) How about causality? Does good governance produce greater happiness? If so, how?

\subsection{Plan of this Paper}

The concept of good governance, its measurement and available data on that matter, are discussed in Sect. 2. Happiness is similarly discussed in Sect. 3. The answers to each of the 
above mentioned research questions are discussed in Sect. 4. The results are discussed in Sect. 5 and conclusions are presented in Sect. 6.

\section{Good Governance in Nations}

\subsection{Concept}

I follow Helliwell and Huang and use the terms governance and government as equivalents. This is acceptable since both terms are very broad, including administration by governments and their legislation and jurisdiction.

The World Bank defines governance as follows: "governance consists of the traditions and institutions by which authority in a country is exercised. This includes the process by which governments are selected, monitored and replaced; the capacity of the government to effectively formulate and implement sound policies; and the respect of citizens and the state for the institutions that govern economic and social interactions among them" (Kaufmann et al. 2008, p. 7). The following aspects of good governance are discerned (ibid. p. 7, 8).

Voice and Accountability The extent to which a country's citizens are able to participate in selecting their government, as well as freedom of expression, freedom of association, and a free media.

Political Stability and Absence of Violence Perceptions of the likelihood that the government will be destabilized or overthrown by unconstitutional or violent means, including domestic violence and terrorism.

Government Effectiveness The quality of public services, the quality of the civil service and the degree of its independence from political pressures, the quality of policy formulation and implementation, and the credibility of the government's commitment to such policies.

Regulatory Quality The ability of the government to formulate and implement sound policies and regulations that permit and promote private sector development.

Rule of Law The extent to which agents have confidence in and abide by the rules of society, and in particular the quality of contract enforcement, the police, and the courts, as well as the likelihood of crime and violence.

Control of Corruption The extent to which public power is exercised for private gain, including both petty and grand forms of corruption, as well as "capture" of the state by elites and private interests.

\subsection{Measurement}

To assess the above mentioned aspects of quality of governments the World Bank collects data from independent sources produced by different organizations. These data sources consist of surveys of firms and individuals, the assessments of commercial risk rating agencies, non-governmental organizations, and a number of multilateral aid agencies and 
other public sector organizations. ${ }^{1}$ Data were sourced from 33 different sources from 30 different organizations ${ }^{2}$ for 2006 . Scores on these sub-indicators for nations have been constructed and monitored since 1996.

\subsubsection{Data-source}

All these data, background information included, is available at the site of the World Bank; Governance Matters VII: Aggregate and Individual Governance Indicators for 1996-2007; as published in "World Bank Policy Research Working Paper 4654, June 2008"33 (Kaufmann et al. 2008).

\subsubsection{Validity}

To check the validity of the data for technical quality I compared it with the "Failed State Index" (Foreign Policy Magazine 2007). Attributes of state failure are loss of physical control of territory, loss of monopoly on the legitimate use of force, erosion of legitimate authority to make collective decisions, and inability to provide reasonable public services and the inability to interact with other states as a full member of the international community. The concepts of technical quality and state failure are similar and scores for technical quality and the "Failed State Index", are highly correlated ( $r=+0.92$ in 2006). To check the validity of the data for democratic quality I compared these data with data of the Political Rights Index (Freedom house 2007). The index measures the degree of freedom in the electoral process, political pluralism and participation, and functioning of government. The concepts democratic quality and political rights are very similar, and scores for democratic quality and political rights are also highly correlated $(r=+0.71$ in 2006). Such high correlations are indications of validity, even if we keep in mind that the World Bank used political rights data to measure democratic quality, in particular voice and accountability.

\footnotetext{
${ }^{1}$ For a recent discussion see "Governance Indicators: Where Are We, Where Should We Be Going?", by Kaufmann and Kraay (2008).

2 The World Bank transforms this information into scores for each of the six sub-indicators with a mean of 0 and a standard deviation of 1 in the original sample of 212 nations and regions (standardized $z$-scores, approximately between -2.5 and +2.5 ; indicating relative positions in a specific year, in my sample in 2006).

${ }^{3}$ I will consider the data on governance as "external data", or as a starting point, without making any effort to explain differences. One observation, however, deserves some attention. We can observe that western nations get the highest scores for government qualities (see Figs. 1,2). We may speculate that the principle of the separation of three independent powers for legislation, administration and jurisdiction provide for an explanation. This principle of the "Trias Politica" was introduced by Montesquieu in 1748 before the American and French revolution. Since then this principle has had a positive impact on nation building and institutionalization in western nations. It has contributed directly to regulatory quality and rule of law, and, more indirectly, to political stability and control of corruption. In most other nations in the world the struggle against repression by some social class, or a colonial power, has been an alternative driver for nation building and institutionalization. In many nations this has eventually led to the formation of one political party with a very dominant position. In such nations the separation of powers is obviously problematic. Many nations are still in such situations, or in their aftermath.
} 


\section{Happiness in Nations}

\subsection{Concept}

Following Veenhoven (1984) I define happiness as 'the degree to which an individual judges the overall quality of his or her life as a whole favourably'; in other words 'how much one likes the life one lives'.

\subsection{Measurement}

Since happiness is defined as something that an individual has in mind, it can be measured using questions. Many different questions ar e used; for an overview see the item bank in the World Database of Happiness (Veenhoven 2008a). The present analysis draws on responses to a survey question, developed by Cantril (1965), which reads as follows:

Suppose we say that the top of the ladder represents the best possible life for you and the bottom of the ladder represents the worst possible life for you. Where on this ladder do you feel you personally stand at the present time? Please use this card to help you with your answer.

$\begin{array}{ccccccccccc}0 & 1 & 2 & 3 & 4 & 5 & 6 & 7 & 8 & 9 & 10 \\ \text { Bottom of the ladder } & & & & & & & \\ \text { Top of the ladder }\end{array}$

The formulation "best and worst possible life" invites respondents to take into account all relevant domains of their life, like social relations, work, housing, leisure and so on. This question invites to a comparative appraisal of life and measures the cognitive dimension of happiness in the first place. As such it is classified as an indicator of "contentment" in the Item Bank of the World Database of Happiness (Veenhoven 2008a). The question used by Helliwell and Huang is different, and asks how "satisfied" one is with one's own life as a whole. In the item bank this question is classified as an indicator of "overall happiness" (item type 122).

\subsubsection{Data-source}

The question developed by Cantril has figured in many national surveys and has been used since 2006 in the Gallup World Poll. All findings gathered with this question are brought together in the collection "Happiness in Nations" under item type 31 (Veenhoven 2008b). This analysis draws on that source and uses all the findings for the year 2006.

\subsubsection{Validity}

Previous research has shown that questions about overall contentment and life-satisfaction produce adequate information in terms of validity and reliability (Schyns 2003). 


\section{Good Governance and Happiness in Nations}

\subsection{Happier with Good Governance?}

The first question (a) is whether the earlier found positive correlation between good governance and average happiness in nations observed by Helliwell and Huang, is replicated in this larger sample of nations and using a different measure of happiness. This appears to be the case. The relationship is clearly positive and quite strong. See Figs. 1 and 2 , which show a clear pattern with few outliers. The relationship between governance and happiness is quite robust.

\subsection{Are Technical and Democratic Aspects of Governance Equally Strongly Related to Happiness?}

Average happiness appears to be more connected with the technical quality of governance than with its democratic quality (question $\mathrm{b}$ ). The zero-order correlation ${ }^{4}$ between average happiness and technical quality is +0.75 , but this correlation is lower for democratic quality: $r=+0.60$. The partial correlation ${ }^{5}$ between happiness and technical quality remains high, if controlled for democratic quality $\left(r_{\mathrm{p}}=+0.58\right)$, while the partial correlation between happiness and democratic quality becomes negative $\left(r_{\mathrm{p}}=-0.17\right)$, if controlled for technical quality.

\subsection{Are the Relationships Linear?}

The relations between happiness and technical and democratic quality are presented in Figs. 1 and 2 respectively (question c). For technical quality we see in Fig. 1 a linear pattern ${ }^{6}$; there is no clear pattern of diminishing or increasing returns of technical good governance. Consequently a quadratic function does not fit the data substantially better than a linear one. ${ }^{7}$

The relation between happiness and democratic quality is presented in Fig. 2. There is a clear pattern of increasing returns of democracy. Consequently a quadratic function creates a better fit than a linear one. ${ }^{8}$

In the right top sections of Figs. 1 and 2 we also see better correlations than in the bottom left sections, i.e., scores are closer to the fit-lines. These differences are quantified in Table 1, in which correlations are presented in groups with comparable numbers of

\footnotetext{
4 A zero-order correlation is the correlation between two variables "as such", without taking into account the effect of any other variable $(s)$. A partial correlation measures the correlation between two variables with the effects of one (or more) variable $(s)$, interaction effects included, controlled or removed.

5 See footnote 4 .

6 The qualification "linear" is somewhat debatable since one might argue about the level of happiness as a statistical variable: Is it just ordinal or is it interval? Linearity only makes sense if we see happiness as a variable at interval level. I follow this line; knowing that using a 0-10-scale supports this approach.

7 A linear function explains $57 \%$ of the variance ( $R$ squared) in average happiness, a quadratic function $58 \%$.

8 A linear function explains $36 \%$ of the variance ( $R$ squared) in average happiness, a quadratic function $43 \%$.
} 


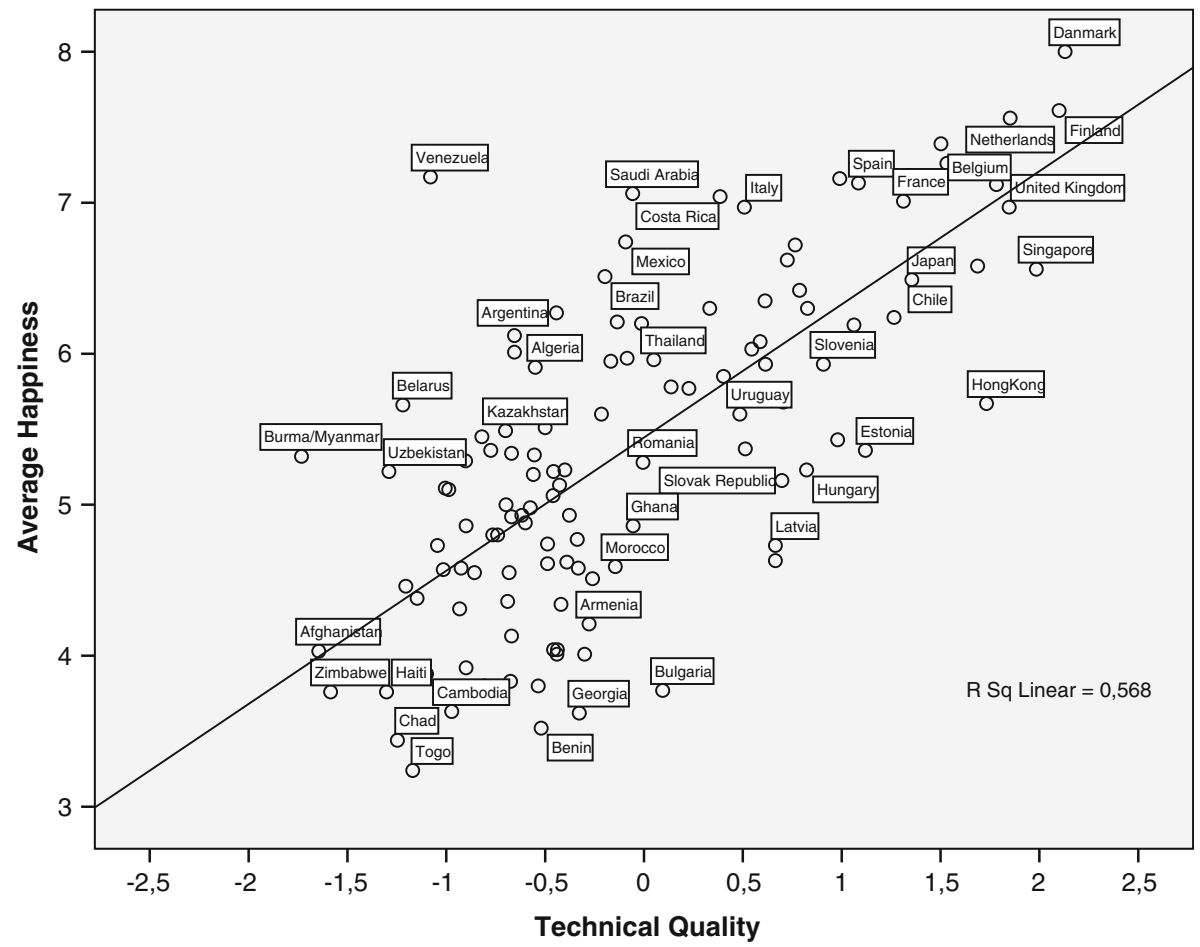

Fig. 1 Technical quality of governance and average happiness in nations in 2006

nations at different levels of technical governance. ${ }^{9}$ The correlations are substantially weaker in the group of 43 nations with the lowest scores on technical quality. The correlations are higher and become substantial in groups of nations with higher levels of technically good governance. Nations seem to need some minimal level of technical competence when it comes to governance before their qualities can develop any substantial correlations with happiness. This minimal level is somewhat higher for democratic quality than for technical quality. Once this minimal level for democracy is reached, both qualities have positive correlations with happiness. The increasing returns of democracy are probably an outcome of interaction effects between technical quality and democracy. In a metaphor: technical quality is the engine of governments and democracy is a steering mechanism. The engine has to start first but together they achieve the best outcomes for happiness.

\footnotetext{
${ }^{9}$ I do report the significance in the tables $(* p<0.05$; ** $p<0.01$ ). This is however somewhat debatable. Significance is the chance that the correlation observed in the sample does not correspond with the correlation in the population from which the sample was drawn. My set of nations is not a random sample of all nations; nations were included if the required data was available. I report the significance as produced by SPSS only to facilitate the assessment of differences.
} 


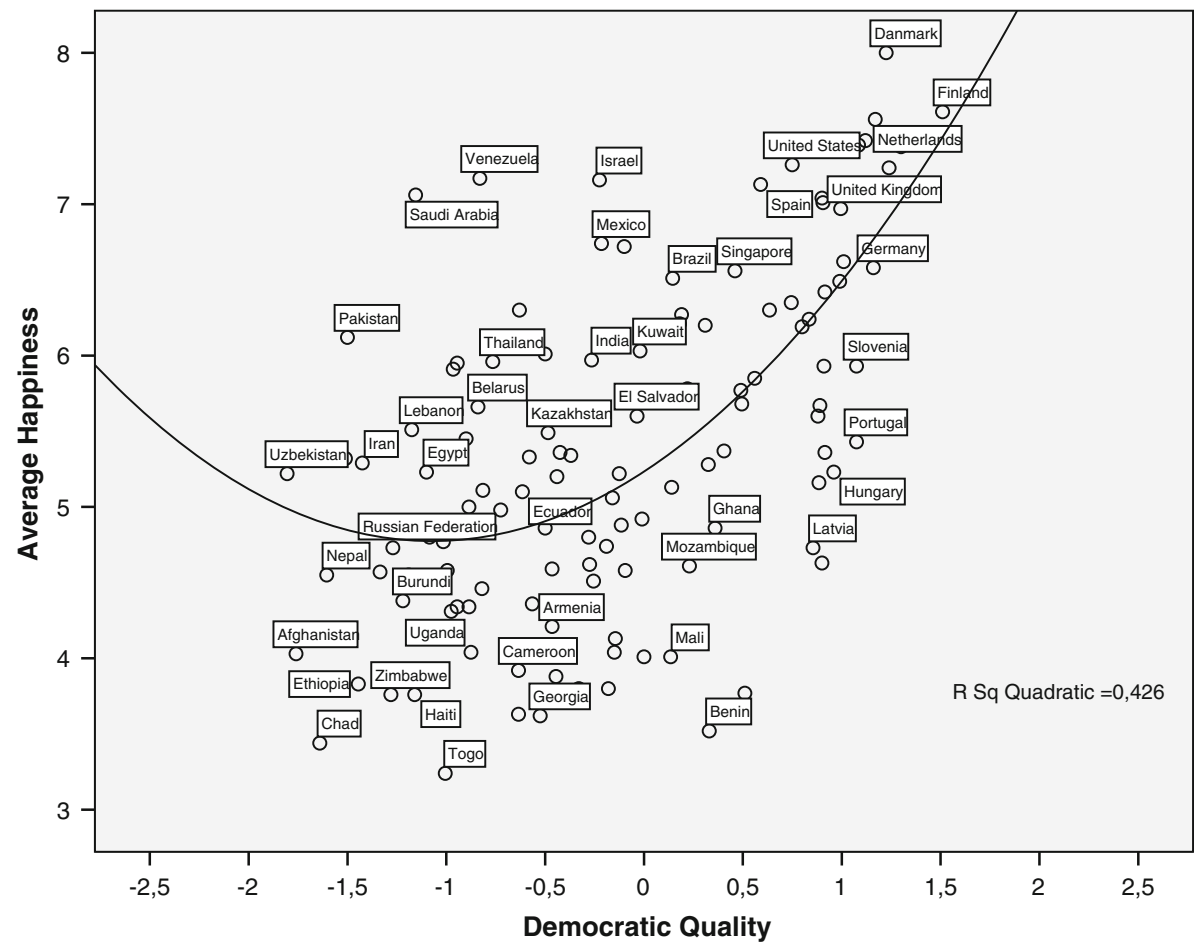

Fig. 2 Democratic quality of governance and average happiness in nations in 2006

Table 1 Correlations between good governance and average happiness at different levels of technical quality, 127 nations in 2006

\begin{tabular}{llll}
\hline Government quality & \multicolumn{3}{l}{ Correlations between government qualities and average happiness } \\
\cline { 2 - 4 } & \multicolumn{2}{l}{ Level of technical quality } & Low \\
\cline { 2 - 4 } & High & Medium & 43 \\
\hline$N$ & 41 & 43 & +0.27 \\
Technical quality & $+0.71^{* *}$ & $+0.51^{* *}$ & +0.13 \\
Democratic quality & $+0.32^{*}$ & +0.07 &
\end{tabular}

High standardized score $>+0.50$, medium $z$-score $<+0.50$ and $\geq-0.55$, low $z$-score $<-0.55$

$* p<0.05 ; * * p<0.01$

\subsection{Are the Correlations Universal?}

To test the assumption that good governance is only important within the context of a "western culture" (question d), I compared the correlations between good governance and average happiness in groups of nations in different parts of the world with different cultures. The results are presented in Table 2. There is some variation in the correlations, but all the correlations point in the same direction: better government goes together with 
Table 2 Correlations between good governance and average happiness in different parts of the world, 127 nations in 2006

\begin{tabular}{lrll}
\hline Part of the world & $N$ & \multicolumn{2}{l}{ Correlations between government qualities and average happiness } \\
\cline { 2 - 4 } & \multicolumn{2}{c}{ Technical quality } & Democratic quality \\
\hline Western nations & 21 & $+0.70^{* *}$ & $+0.45^{*}$ \\
Eastern Europe & $23+0.40^{*}$ & $+0.46^{*}$ \\
Latin America & $23+0.51^{*}$ & $+0.48^{*}$ \\
Middle East & $11+0.71^{*}$ & +0.27 \\
Asia & $22+0.73^{* *}$ & $+0.65^{* *}$ \\
Africa & $26+0.52^{* *}$ & $+0.39^{*}$ \\
All nations (above +1 in Pacific) & $127+0.75^{* *}$ & $+0.60^{* *}$ \\
\hline
\end{tabular}

$* p<0.05 ; * * p<0.01$

Table 3 Correlations between good governance and average happiness in 56 poor and 56 rich nations in 2006

\begin{tabular}{llll}
\hline Poor and rich nations & $N$ & \multicolumn{2}{l}{ Correlations between government qualities and average happiness } \\
\cline { 3 - 4 } & & Technical quality & Democratic quality \\
\hline Poor nations $^{\mathrm{a}}$ & 56 & $+0.39^{* *}$ & +0.06 \\
Rich nations $^{\mathrm{b}}$ & 56 & $+0.62^{* *}$ & $+0.46^{* *}$ \\
\hline
\end{tabular}

$* p<0.05 ; * * p<0.01$

a Poor $<7,000$ USD purchasing parity per capita in 2006

b Rich $>7,000$ USD purchasing parity per capita in 2006

greater happiness. The correlation is apparently independent of culture. In most subsamples technical quality shows the highest correlations, only in Eastern Europe this is reversed, but not dramatically.

To test whether the correlation depends on the wealth of nations I compared the correlations in poor and rich nations, see Table 3. The outcomes support the conclusion of Helliwell and Huang that technical quality is relatively more important in poor nations and democratic quality is relatively more important in rich nations. I can even specify their assessment: in all nations there is a substantial correlation between happiness and technical quality, but only in rich nations is there a substantial correlation between happiness and democratic quality. The technical quality of governance is not only the most connected to happiness, its relation to happiness is also the most universal.

In a nutshell: the correlations between government qualities and happiness do not depend on culture. The correlation between technical quality and happiness does not depend on wealth either, but the correlation between democratic quality and happiness is limited to relatively rich nations. Technical quality of governance apparently precedes democracy.

\subsection{Do the Correlations Depend on Size of Government?}

Having established that people are happier in countries with better governments, the next question is whether this relation depends on the size of government (question e). Size of 
Table 4 Correlations between good governance and average happiness, zero-order and controlled for aspects of size, 127 nations in 2006

\begin{tabular}{lrll}
\hline Aspects of size, partialled out & $N$ & $\begin{array}{l}\text { Correlations between government qualities and average } \\
\text { happiness }\end{array}$ \\
\cline { 3 - 4 } \cline { 3 - 4 } & & Technical quality & Democratic quality \\
\hline Zero-order correlation & 127 & $+0.75^{* *}$ & $+0.60^{* *}$ \\
Government consumption partialled out & 113 & $+0.72^{* *}$ & $+0.56^{* *}$ \\
Transfers and subsidies partialled out & 96 & $+0.67^{* *}$ & $+0.46^{* *}$ \\
Government enterprises partialled out & 110 & $+0.68^{* *}$ & $+0.45^{* *}$ \\
Tax rate partialled out & 97 & $+0.74^{* *}$ & $+0.60^{* *}$ \\
\hline
\end{tabular}

$* p<0.05 ; * * p<0.01$

government is a complex concept. The Fraser Institute makes a distinction between four aspects and applies separate sub-indicators to measure these aspects. The four aspects are:

- General government consumption and spending, as a percentage of total consumption

- Transfers and subsidies as a percentage of GDP

- Government enterprises and investment as a percentage of total investment

- Top marginal tax rate and income threshold at which it applies

The zero-order and partial correlations ${ }^{10}$ between government qualities and average happiness, after controlling for the four aspects of the size of governments, are presented in Table 4. We see that the correlations remain high. Apparently, the correlation between government qualities and average happiness are independent of aspects of size.

It is informative to answer the reversed question as well: Do the relationships between aspects of size and happiness depend on the quality of government? The zero-order correlation between "government enterprises and investments" and happiness is very negative $(r=-0.55)$ but the other correlations are positive $(+0.44,+0.53$ and +0.25 , see Table 5$)$. Yet, these correlations are much reduced after control for government quality. ${ }^{11}$ Only the partial correlation between government consumption and happiness remains at a substantial level if controlled for democratic quality. This is another indication that democratic quality is less influential compared to technical quality in its association with happiness.

In sum: the relations between quality of government and average happiness do not depend on size of government, while the relations between size of government and happiness fully depend on the quality of government. Quality of government clearly beats size of government in its association with average happiness.

\subsection{How About Causality?}

There are three possible explanations for the positive correlation between government quality and happiness (question f):

\footnotetext{
10 See footnote 4.

11 I can make the same point by comparing the relation between aspects of size and happiness at different levels of technical quality (same groups as in Table 1). The relation between taxation and happiness is positive at a high level $(+0.32)$ but negative at a low level $(-0.21)$. The relation between government consumption and happiness is positive at the high level $(+0.26)$ but disappears at the low level $(+0.05)$.
} 
Table 5 Correlations between size of government and average happiness in 127 nations 2006

\begin{tabular}{|c|c|c|c|c|}
\hline \multirow[t]{2}{*}{ Aspects of government size } & \multirow[t]{2}{*}{$N$} & \multicolumn{3}{|c|}{ Correlations between aspects of size and average happiness } \\
\hline & & $\begin{array}{l}\text { Zero- } \\
\text { order }\end{array}$ & $\begin{array}{l}\text { Technical quality } \\
\text { partialled out }\end{array}$ & $\begin{array}{l}\text { Democratic quality } \\
\text { partialled out }\end{array}$ \\
\hline Government consumption & 113 & $+0.44 * *$ & +0.14 & $+0.28 *$ \\
\hline Transfers and subsidies & 96 & $+0.53 * *$ & +0.15 & +0.27 \\
\hline $\begin{array}{l}\text { Government enterprises and } \\
\text { investments }\end{array}$ & 110 & $-0.55^{* *}$ & -0.19 & -0.26 \\
\hline Top marginal tax rate & 97 & $+0.25^{* *}$ & +0.05 & +0.05 \\
\hline
\end{tabular}

$* p<0.05 ; * * p<0.01$

\subsubsection{Spurious Correlation?}

In this explanation, there is no causal relation between good governance and happiness, but are both variables dependent on a third variable. 'Wealth' and 'social trust' could be such variables since they are likely to affect both average happiness and the quality of government in a nation. Yet this cannot be the whole story since the correlations between government quality and happiness does not completely disappear if the effects of wealth or social trust are accounted for first. ${ }^{12}$ More such factors may be involved, but for the time being at least part of the correlation seems to be due to a causal relationship.

\subsubsection{Effect of Happiness?}

In this explanation happiness affects quality of government rather than vice versa. Various effects can be involved: e.g., happy citizens being more apt to vote for investment in public good and less apt to obstructive behavior. Such explanations fit the literature on benefits of happiness (Lyubomirsky et al. 2005). Still, this is unlikely to be the whole story, for instance because good governance roots in historical developments, which were not always particularly happy. ${ }^{13}$

\subsubsection{Effect of Government Quality?}

The last explanation is that better government makes happier citizens and this explanation appeals most to common sense. There must be some truth in this explanation, since the above mentioned alternative explanations are insufficient to explain the correlation completely. If so, how does good governance add to average happiness? The data cannot tell us as yet, but we can discern some possible direct and indirect effects.

Possible Direct Effects Good governance can be a source of happiness in itself. It makes a difference if citizens are treated carefully and respectfully. As pointed out by Frey and Stutzer (2005) participation in elections (voice) contributes to happiness, independent of the outcomes. These direct effects are examples of 'procedural utility' (Frey 2008).

\footnotetext{
${ }^{12}$ The correlation between technical quality and happiness of 0.75 is reduced to +0.70 , and +0.11 , if controlled for social trust and wealth respectively. For democratic quality the correlation of 0.60 is reduced to 0.58 and -0.01 . The partial correlations remain higher for technical quality and this is an additional indication that the impact of technical quality is more "autonomous", and, as a consequence, more universal.
}

${ }^{13}$ See footnote 3. 
Possible Indirect Effects Good governments will be more effective in creating conditions that contribute to average happiness in the country, such as material prosperity, good education and safety in the streets. Likewise, competent and democratic governments can create individual freedom, by maintaining stable and predictable conditions that enable people to make their own decisions in life (Veenhoven 1999). This is what Frey (2008) refers to as 'output utility'.

As yet, we cannot really prove that things work that way. Still, path analysis in this set of 127 nations shows that the factors wealth, i.e. purchasing power per capita, gender equality, as measured by the Gender Development Index, and physical safety and healthcare, ${ }^{14}$ may serve as mediating variables in the relation between good governance and happiness. ${ }^{15}$ This interpretation fits much of the earlier research on societal conditions for happiness (e.g. Ott 2005).

\section{Discussion}

The prime aim of this paper was to check whether average happiness is higher in nations where the quality of government is good. I could replicate this earlier finding of Helliwell and Huang in a larger set of nations and using another indicator of happiness. So we can take this relationship as an established fact. What else does the data tell us and what do the findings teach us?

\subsection{Additional Findings}

Helliwell and Huang found that the technical quality of government is relatively more important for poor nations, while democratic quality is relatively more important for wealthier nations. They assume that democracy becomes interesting and important only when government has reached a minimal level of technical quality. I agree with these conclusions and can add that the relationship between technical quality of government and happiness is also more universal. Technical quality is important in all nations, while democracy is only important in rich nations, but even in rich nations it is less connected to happiness than technical quality. Both qualities need a minimal level of technical quality to develop a relation with happiness, but democratic quality needs a higher level than technical quality. Once democracy works, both qualities contribute to average happiness with positive interaction effects.

Another additional finding is that the relation between quality of government and happiness is independent of the size of government, and that the relation between size of government and happiness depends fully on these qualities.

These additional findings were facilitated by the availability of more data. I could use a bigger sample of nations which included more poor nations, and data about happiness as

\footnotetext{
14 These factors provide for a reasonable explanation of the differences in average happiness in 127 nations in 2006. If these factors are used as independent factors in a linear regression they explain $72 \%$ of the variance (adjusted $R$-square). Adding more factors, like economic freedom, economic openness, social trust, or education, does not substantially improve the explanatory value of the regression.

15 The correlation between wealth and happiness is +0.80 and between wealth and technical and democratic quality +0.92 and +0.80 respectively. For gender equality these correlations are $+0.80,+0.76$, and +0.67 . For life-expectancy, as an indicator for safety and healthcare, these correlations are $+0.73,+0.65$, and +0.52 .
} 
contentment with life instead of happiness as life-satisfaction. Data about happiness as contentment have a somewhat higher correlation with objective conditions like wealth (Bjørnskov 2008).

\subsection{Further Research}

Further research, using different measures for happiness and bigger and even more representative samples, is needed to check the general validity of the conclusions presented here. The World Bank has data about government quality in 212 nations and regions, but for happiness there are only data for about 130 nations. Bigger samples provide for better possibilities to distinguish between nations, like western nations and nations with a colonial or communist history. Cross sectional research for specific groups of nations and individuals should create a better understanding of general and specific interactions between government qualities, average happiness, wealth and social trust. In addition, longitudinal research is needed. Such research requires a systematic and prolonged collection of data in accessible data-bases, such as the World Database of Happiness.

\subsection{Relevance of the Findings}

The differences in average happiness in nations are impressive and alarming, in 2006 they ranged from 3.24 in Togo to 8.00 in Denmark. Governments play a dominant role in creating such differences. In discussions about this role there has always been a lot of attention for the actual policies to be pursued: what governments should do to create optimal conditions for (subjective) well-being. Governments that aim at greater happiness for a greater number, however, should not only focus on what they do, but they should also focus on how they function.

The technical and democratic qualities of governance appear to be more important for happiness than the size of a government. The impact of these qualities is independent of size while the impact of size depends on these qualities. This last point is important for discussions about the optimal size of governments and optimal levels of government spending. See for instance the contributions by NG and Ho (2006)and Bjørnskov et al. (2007). In NG's assessment public expenditures are too low because people underestimate the utility of public goods. Bjørnskov et al empirically found a negative association between happiness and the size of governments. These authors seem to underestimate the crucial role of government qualities for the relation between size and happiness.

This all underlines the importance of technical and democratic government quality in general, and in particular the importance of technical quality of governance for happiness in poor nations. This is interesting because improving the technical quality of governance is probably less controversial than increasing or decreasing the size of a government, or changing the rules for democracy. There are many ways to improve the technical quality of governments $^{16}$ and the World Bank and other international organizations like the UN, the IMF and the OECD, provide practical guidelines and support. Each nation, however, will

\footnotetext{
16 Three interesting "down-to-earth" options for poor nations are:

a. The registration of property rights, in particular for real estate, i.e., have a land registry. As has been demonstrated by De Soto (2000) this is an important condition for economic development.

b. To register people, i.e., set up registrar's offices, as a necessary condition to organise adequate public education and health services.

c. To develop and implement general principles of good governance, to achieve decent and respectful relations between government institutions and citizens.
} 
have to improve the quality of its own governance in ways that fit its specific problems and opportunities.

\section{Conclusion}

People live happier in well governed nations and this seems to be at least partly due to a causal effect of good governance on happiness. Investment in quality of government is therefore a good way to create greater happiness for a greater number.

\section{References}

Bjørnskov, C. (2008). How comparable are the Gallup World Poll Life Satisfaction Data? Journal of Happiness Studies, Published online November 4, 2008.

Bjørnskov, C., Dreher, A., \& Fischer, J. (2007). The bigger the better? Evidence of the effect of government size on life satisfaction around the world. Public Choice, 130, 3-4.

Cantril, H. (1965). The pattern of human concerns. New York: New Brunswick.

De Soto, H. (2000). The mystery of capital: Why capitalism triumphs in the west and fails everywhere else. London: Bantam Press.

Easterlin, R. (1974). Does economic growth improve the human lot? Some empirical evidence. In P. A. David \& M. W. Reder (Eds.), Nations and households in economic growth: Essays in honour of Moses Abramovitz. New York: Academic Press.

Foreign Policy Magazine. (2007). The failed state index. Washington, DC: Carnegie Endowment for International Peace. www.foreignpolicy.com.

Freedom House. (2007). Freedom in the World, 2007 Edition.

Frey, B. S. (2008). Happiness, a revolution in economics. Cambridge: The MIT Press.

Frey, B. S., \& Stutzer, A. (2005). Beyond outcomes: Measuring procedural utility. Oxford: Economic Papers.

Gwartney, J. D., \& Lawson, R. A. (2006). Economic freedom of the world. Annual report. Fraser Institute, Vancouver, Canada. www.freetheworld.com/206/2006dataset.xls.

Helliwell, J., \& Huang, H. (2008). How's your government? International evidence linking good government and well-being. British Journal of Political Science, 38, 595-619.

Inglehart, R., et al. (2004). World Values Surveys and European Values Surveys, 1999-2001 (Computer file) ICPSR version. Ann Arbor, MI: Institute for Social Research (producer), 2002. Ann Arbor, MI: Interuniversity Consortium for Political and Social Research (distributor), 2004.

Kaufmann, D. (2005). Back to basics, 10 Myths about governance and corruption. Finance \& Development, $42(3)$, myth 4.

Kaufmann, D., \& Kraay, A. (2008). Governance indicators: Where are we, where should we be going? World Bank Research Observer.

Kaufmann, D., Kraay, A., \& Mastruzzi, M. (2008). Governance matters VII: aggregate and individual governance indicators, 1996-2007”. World Bank Policy Research Working Paper No. 4654, World Bank 2008. www.govindicators.org.

Layard, R. (2005). Happiness: Lessons from a new science. New York, USA: The Penguin Press.

Lyubomirsky, S., Diener, E., \& King, L. (2005). The benefits of frequent positive affect: Does happiness lead to success? Psychological Bulletin, 131, 803-855.

Martin, P. (2005). Making happy people: The nature of happiness and its origins in childhood. London: Fourth Estate, Harper Collins Publishers.

New Economics Foundation. (2004). Well-being manifesto for a flourishing society. http://www. neweconomics.org.

NG, Y., \& Ho, L. S. (Eds.). (2006). Happiness and public policy. New York: Palgrave MacMillan.

Ott, J. C. (2005). Level and equality of happiness in nations: Does greater happiness of a greater number imply greater inequality in happiness? Journal of Happiness Studies, 6(4), 397-420.

Schyns, P. (2003). Income and life satisfaction: Chapter 2: Life satisfaction: the concept, its measurability and cross-national comparability. Netherlands: Eburon, Delft.

Veenhoven, R. (1984). Conditions of happiness. Dordrecht: Kluwer. 
Veenhoven, R. (1999). Quality of life in individualistic society, a comparison of 43 nations in the early 1990's. Social Indicators Research, 48, 157-186.

Veenhoven, R. (2008a). World database of happiness, item bank. Erasmus University Rotterdam. Assessed March 2009 http://www.worlddatabaseofhappiness.eur.nl.

Veenhoven, R. (2008b). World database of happiness, distributional findings in nations. Erasmus University Rotterdam. Assessed March 2009 http://www.worlddatabaseofhappiness.eur.nl. 